\title{
Children's Vulnerability to Sexual Violence During COVID-19 in Kenya: Recommendations for the Future
}

\author{
Laura M. Stevens ${ }^{1}$, James C. Rockey ${ }^{1}$, Sarah R. Rockowitz ${ }^{1}$, Wangu Kanja ${ }^{2}$, \\ Melissa F. Colloff ${ }^{1}$ and Heather D. Flowe ${ }^{1 *}$ \\ ${ }^{1}$ School of Psychology, University of Birmingham, Birmingham, United Kingdom, ${ }^{2}$ Wangu Kanja Foundation, Nairobi, Kenya
}

\section{OPEN ACCESS}

Edited by:

Vassiliki Benetou,

National and Kapodistrian University

of Athens, Greece

Reviewed by:

Federica Facchin,

Catholic University of the Sacred

Heart, Milan, Italy

Safieh Jamali,

Jahrom University of Medical

Sciences, Iran

*Correspondence:

Heather D. Flowe

h.flowe@bham.ac.uk

Specialty section:

This article was submitted to

Quality of Life,

a section of the journal

Frontiers in Global Women's Health

Received: 18 November 2020

Accepted: 28 January 2021

Published: 24 February 2021

Citation:

Stevens LM, Rockey JC,

Rockowitz SR, Kanja W, Colloff MF

and Flowe HD (2021) Children's

Vulnerability to Sexual Violence During

COVID-19 in Kenya:

Recommendations for the Future.

Front. Glob. Womens Health

2:630901.

doi: 10.3389/fgwh.2021.630901
This article discusses the latest research that reveals that children seem to be facing new risks of sexual violence in Kenya during the COVID-19 pandemic. The evidence suggests there have been changes in patterns of sexual offenses against children coincident with lockdowns, curfews, and school closures. In particular, emerging evidence from Kenya suggests that child victims are younger, more likely to be victimized by a neighbor in a private residence, and in the daytime, compared to pre-pandemic. We conclude that situational crime prevention strategies that focus on providing alternative safe venues to reduce offending opportunities must be a central part of a public health approach to reduce children's vulnerability during crises such as COVID-19.

Keywords: sexual violence against children, COVID-19, situational crime prevention, public health approach, offender versatility, Kenya

\section{INTRODUCTION}

During the COVID-19 pandemic, many countries have implemented emergency measures to reduce the spread of the disease. However, these measures may be intensifying sexual and genderbased violence [SGBV; (1)]. UN Women (2) found that in the last 12 months, 243 million women aged 15-49 had been subjected to SGBV by an intimate partner. The UN Population Fund (3) estimates that, after 6 months of emergency measures, there will be 31 million additional SGBV cases worldwide. SGBV is exacerbated during crisis situations because of heightened gender inequality and financial pressures (4), as well as difficulties in accessing relevant medical and legal services (5). COVID-19 has further intensified SGBV due to lockdown measures, effectively trapping victims in their homes with potential abusers [for a review of GBV during COVID-19, see (4)].

Specific concerns have been highlighted for COVID-19 and sexual and reproductive health. For example, the postponement of programmes designed to protect girls from female genital mutilation (FGM) and child marriage due to COVID-19 is estimated to lead to two million more cases of FGM and 13 million more child marriages over the next 10 years (3). This perspective piece focuses on low- and middle-income countries (LMICs), and specifically Kenya. This is because there is political 
good will to research and respond to SGBV in Kenya following President Kenyatta's call to action in the wake of increasing SGBV in the country (6). There is also mounting empirical evidence about new patterns of violence against children, owing to the data collection infrastructure established by the Survivors of Sexual Violence in Kenya Network (7). In Kenya, a reported $29 \%$ of women are married before the age of 18 (8). This is expected to increase during COVID-19, as financial strain leads families to marry their daughters to reap economic benefits in contexts where bride price is practiced $(9,10)$. Additionally, the Kenyan Democratic and Health Survey (8) estimates that 21\% of Kenyan women aged 15-49 years had experienced female genital mutilation (FGM). During COVID-19, school closures and limited police presence have left young girls increasingly exposed to FGM (11). A report from October 2020 found that 2,800 12 year-old girls were paraded through the Kuria village in Kenya to showcase their initiation, despite legislation prohibiting FGM (11).

In this article, we discuss how the latest research reveals that children in LMICs such as Kenya seem to be facing new risks of sexual violence during the pandemic. In particular, while previous research has highlighted the adverse consequences of suspending programmes designed to prevent SGBV, we will highlight that patterns of offending behavior have potentially changed following the implementation of lockdowns, curfews, and school closures. These new risk factors must be considered in order to protect children from sexual violence.

\section{Child Victims in Low- and- Middle Income Countries During COVID-19}

Whilst the impact of COVID-19 on sexual violence and children is a global issue, it is of particular concern in LMICs. For example, South Africa saw a $61.6 \%$ increase in child abuse disclosures during COVID-19 in comparison to the previous year, with emotional abuse being the most frequent, followed by physical and sexual abuse (12). Additionally, emerging findings suggest that measures used to control COVID-19 in Kenya have exacerbated sexual violence against children, particularly girls. Kenya had high rates of victimization pre-COVID-19, with the National Violence Against Children Survey (13) finding that $13.5 \%$ of girls and $2.4 \%$ of boys experience sexual violence by the age of 17. However, this escalated further with the emergency measures introduced to prevent COVID-19 spread, including a nightly dusk-to-dawn curfew, travel restrictions, and school closures $(6,7,14)$.

Ongoing evidence collection by the Survivors of Sexual Violence in Kenya Network suggests that COVID-19 has changed patterns of sexual violence against children $(7,15)$. First, child sexual violence victims are now age 12 on average (7), compared to 16 previously (13). This finding is corroborated by evidence from forensic medical examiners at gender-based violence recovery centers in Kenya who have noted that survivors attending hospitals for SGBV violations during COVID-19 are now younger and mostly below the age of 16 (16).

Second, school closures and reduced parental monitoring have coincided with an increase in offenses perpetrated by individuals known to the survivor. Offenses are more often being perpetrated by neighbors during the pandemic compared to before ( 42 vs. $16 \%)(7,13)$. There are reported cases wherein neighbors have gained access to children through the ruse of providing educational resources, such as laptops and internet access, during school closures $(7,15)$. Worryingly, it is increasingly being recommended that neighbors should be utilized during COVID19 to help identify and protect victims, and to aid in reporting incidences [e.g., $(1,17)]$. However, prevention and protection programmes must urgently take heed of emerging evidence that neighbors are frequent perpetrators of violence during the pandemic in Kenya.

Third, the timing and location of sexual violence offenses seem to have changed during the COVID-19 pandemic. Offending during the pandemic in Kenya most often is taking place during the day ( $76 \%$ of all cases) when children would have previously been at school (7). Additionally, most sexual offenses against children during COVID-19 appear to be occurring in private locations ( $71 \%$ of all cases), with most of these offenses occurring in the perpetrator's home (65\%), followed by the child's own residence $[29 \%$; (7)]. This is in stark contrast to pre-COVID-19, when few offenses against children occurred in private $(24.5 \%$ of all cases), and few attacks occurred at the perpetrator's home (14.9\%) or the child's residence [5.4\%; (13)].

\section{DISCUSSION}

School closures are associated with many consequences for children, including a lack of access to educational content with $80 \%$ of 18 million children not accessing the radio or online content provided by the Government during this time (18). As a result, Kenya's Education Minister has announced that students will be required to repeat this academic year (19). Additionally, the above findings and other previous research highlights that school closures are related to increased sexual violence against children. Whilst boys and girls are both victims of sexual violence, sexual violence disproportionately affects girls with $13.5 \%$ of girls experiencing sexual violence by the age of 17 in comparison to $2.4 \%$ of boys (13).

Goulds et al. (20) studied school closures during the Ebola epidemic in Sierra Leone in 2014-15, finding that closures left children at greater risk of rape, and led to $65 \%$ increase in teenage pregnancies (21). Furthermore, research has found that the financial strain experienced during pandemics increases the number of young girls being forced into child marriage and highrisk work to provide food for their families. Moreover, there is heightened concern that school closures due to COVID-19 will increase children's vulnerability to violence and abuse (22).

Young girls are also at an increased risk of FGM and child marriages whilst they are not able to access the safety of their school networks $(23,24)$. Schools may offer sanctuary to young girls escaping child marriages and FGM, providing them with shelter, food, education, and the chance of a better future (25). However, school closures during the pandemic may result in young girls being sent home to families which will exploit them, if no one else in the community is able to protect 
them adequately from COVID-19 or afford to sponsor them (25). Additionally, financial pressures exacerbated by COVID-19 increase the proportion of child marriages, as families require the bridal price paid for their daughters to support their families (23, 25). Child marriages, like rape, lead to teenage pregnancies, with one area in Kenya reporting that 4,000 teenagers have become pregnant during the pandemic (6). Moreover, it is clear that the school closures implemented to reduce the spread of COVID19 has had far reaching consequences, which disproportionately affect young women and more protective measures need to be endorsed to reduce this (26).

\section{Versatility of Sexual Offending}

Sexual offender specialization and versatility have been widely studied to understand how to prevent and protect people from violence. Shifting patterns in the "who, what and where" of sexual violence seen during COVID-19 illustrate the versatility of sexual offending, which means that offenders adjust their offending behaviors to correspond with the offending opportunities that arise (27). Most sexual offenders, including child molesters, are versatile (28). Many sexual offenders do not have a predilection toward victims of a specific age range, but rather victimize people across a range of ages [(29); see also (30)]. Most concerning is that versatile offenders pose a higher risk for future sexual and violent recidivism than non-versatile offenders (31). Thus, it is important for policy makers and duty bearers to recognize that sexually violent behavior evolves with the circumstances. The COVID-19 pandemic has resulted in more unsupervised children and offenders being close to home, likely providing increased opportunities for offenders to target and violate especially younger children. Therefore, protection strategies need to be reviewed and adapted to changing risks.

\section{Protecting Children: Situational Crime Prevention}

Situational crime prevention strategies can potentially reduce immediate offending opportunities that are arising from school closures $(32,33)$. Situational crime prevention strategies consider key environmental factors that are associated with offending opportunities, and design prevention measures that restrict opportunities, whilst also increasing the risks of offending and limiting the benefits (33-35). One example of situational crime prevention commonly used to address SGBV is the implementation of safe refuge locations, with these primarily run by community groups $(34,36)$. These shelters increase the safety of survivors whilst also promoting community participation in their protection (36). The prioritization of refuge centers for SGBV survivors is vital during COVID-19 to prevent survivors being isolated with their abusers, as many perpetrators are family members $(1,7,16,37)$.

In combination with temporary housing for survivors, alternative safe environments for children are required during the day whilst schools are closed. This will limit offenders' opportunities to access children during extreme circumstances such as a pandemic (21). These safe spaces for children should be developed by trusted community groups, as they have advanced knowledge of the local population and their needs
(34). Alternative safe environments were used in Sierra Leone during the Ebola pandemic (21). In this context the protective space was used for social support, education on sexual and reproductive health, and vocational training to increase the economic potential of the young girls (21). Programs such as these could be implemented in LMICs during COVID-19 to reduce the sexual exploitation of young girls and prevent school dropouts due to teenage pregnancies [(21); see (7) for further recommendations].

One limitation of the situational crime prevention framework is that by limiting an offender's opportunity to target certain victims, offenders may instead pursue other types of victims [e.g., new age groups or another gender; (35)]. This was found in Sierra Leone, where only younger girls accessed the safe space; thus, offenders began violating older girls instead (21). Moreover, alongside crime prevention methods, long-term holistic societal changes are needed to prevent this displacement, such as by tackling social and economic factors that correlate with crime (35).

Violence against women is a systemic issue. Attitudes towards gender equality license SGBV. Therefore, it is essential a wider public health approach is taken to tackle SGBV $(38,39)$. A public health approach aims to create an environment where all citizens are safe and healthy (38). Therefore, a public health approach would work to adapt a culture of gender equality, where the human rights of individuals were respected to promote safety. This can be achieved alongside a situational crime prevention framework by the implementation of wider community programs, such as education programmes on gender equality, healthy relationship formation, and bystander intervention, as well as economic strengthening programs, such as cash transfers and micro-finance training (40). These programs would work to implement a culture of zero tolerance toward violence, whereby all are equal and financially viable.

However, one weakness regarding research into crime prevention methods is that there is limited empirical data from low-resource environments. It is imperative to increase the capacity of countries like Kenya and South Africa to document cases and research patterns of violence over time (41). This information can be used to monitor and evaluate crime prevention techniques and suggest how they can be improved in the future.

\section{CONCLUSION}

Emerging evidence from Kenya suggests that COVID-19 and the associated curfews and school closures have coincided with children being violated at a younger age, and increasingly in private residences by individuals known to them, namely neighbors. It is critical that crisis management plans for COVID19 are altered to explicitly provide for the protection of children, such as by providing alternative safe environments during school closures and increasing the provision of refuge centers. Continued surveillance of patterns of sexual violence against children is vital to identify new risk factors and protect children 
during COVID-19. Whilst the data presented here are specific to the Kenyan context, these patterns and recommendations should be applied to protecting children globally, especially in other LMIC contexts.

\section{DATA AVAILABILITY STATEMENT}

The original contributions presented in the study are included in the article/supplementary material, further inquiries can be directed to the corresponding author/s.

\section{REFERENCES}

1. Campbell AM. An increasing risk of family violence during the Covid-19 pandemic: strengthening community collaborations to save lives. Forensic Sci Int Rep. (2020) 2:100089. doi: 10.1016/j.fsir.2020.100089

2. UN Women. COVID-19 and Ending Violence Against Women and Girls. (2020). Available online at: https://www.unwomen.org/-/media/ headquarters/attachments/sections/library/publications/2020/issue-briefcovid-19-and-ending-violence-against-women-and-girls-en.pdf?la=en\&vs= 5006 (accessed November 2, 2020).

3. United Nations Populations Fund. Millions more cases of violence, child marriage, female genital mutilation, unintended pregnancy expected due to the COVID-19 pandemic. UNFPA website. (2020). https://www.unfpa. org/news/millions-more-cases-violencechild-marriage-female-genitalmutilation-unintended-pregnancies (accessed November 2, 2020).

4. Mittal S, Singh T. Gender-based violence during COVID-19 pandemic: a mini review. Front Global Women's Health. (2020) 1:4. doi: 10.3389/fgwh.2020.00004

5. Bellizzi S, Nivoli A, Lorettu L, Ronzoni AR. Human rights during the COVID19 pandemic: the issue of female genital mutilations. Publ Health. (2020) 185:53-4. doi: 10.1016/j.puhe.2020.05.037

6. Bhalla N. Kenya orders probe into rise in violence against women and girls during Pandemic. Thomas Reuters Foundation News. (2020). Available online at: https://fr.reuters.com/article/us-health-coronavirus-kenya-womentrfn/kenya-orders-probe-into-rise-in-violence-against-women-and-girlsduring-pandemic-idUSKBN2472ER (accessed November 2, 2020).

7. Flowe H, Rockowitz S, Rockey J, Kanja W, Kamau C, Colloff M, et al. Sexual and other forms of violence during the Covid-19 pandemic emergency in Kenya: patterns of violence and impacts on women and girls. Zenodo. (2020) 1-26. doi: 10.31234/osf.io/eafwu

8. Kenya National Bureau of Statistics, Ministry of Health. Kenya Demographic and Health Survey 2014. (2014). Available online at: https://dhsprogram. com/publications/publication-FR308-DHS-Final-Reports.cfm (accessed November 2, 2020).

9. Reidy E. Family Assets. Understanding and Addressing Child Marriage in Turkana. UNICEF. (2016). Available online at: https://www.girlsnotbrides.es/ wp-content/uploads/2016/08/UNICEF-Kenya-Family-Assets-in-TurkanaKenya-Feb-2016.pdf (accessed November 2, 2020).

10. Bhalla N. Futures destroyed: COVID-19 unleashes 'shadow pandemics' on Africa's girls. Thomas Reuters Foundation News. (2020). Available online at: https://news.trust.org/item/20200820135640-yl2ii/ (accessed November 2, 2020).

11. Dyer O. FGM: nearly 3000 girls are paraded in Kenya as pandemic hinders control efforts. Br Med J. (2020) 371:m4165. doi: 10.1136/bmj.m4165

12. Childline Gauteng. Covid-19 - Report on help line data lockdown period 27th March 2020 - 30th April 2020. (2020). Available online at: https:// childlinegauteng.co.za/wp-content/uploads/2020/05/2.-Lockdown-Level-5_ CLGP_Stats-Report_Final.pdf (accessed November 2, 2020).

13. Ministry of Labour and Social Protection of Kenya, Department of Children's Services. Violence against Children in Kenya: Findings from a National Survey. Nairobi, Kenya: 2019. (2019). Avaialble online at: https://www.unicef.org/ kenya/sites/unicef.org.kenya/files/2020-07/\%202-VAC\%20Survey\%20WEB. pdf (accessed November 2, 2020)

\section{AUTHOR CONTRIBUTIONS}

LS, HF, and JR drafted the manuscript, which was reviewed by SR, MC, and WK. All authors contributed to the editing of the approved final manuscript.

\section{FUNDING}

This research was funded by an Economic and Social Research Council grant award (ES/T010207/1).

14. UNOHCHR. Kenya: Monitoring Human Rights Impacts of COVID-19 In Informal Settlements. (2020).

15. Rockowitz S, Stevens L, Rockey J, Kanja W, Colloff M, Flowe DH. Patterns of Sexual Violence Among Women and Children During the COVID-19 Pandemic in Kenya. (2021).

16. Johnson K, Green L, Volpellier M, Kidenda S, McHale T, Naimer K, et al. The impact of COVID-19 on services for people affected by sexual and gender based violence. Int J Gynecol Obstetr. (2020) 150:2857. doi: 10.1002/ijgo.13285

17. Jonson-Reid M, Drake B, Cobetto C, Ocampo M. Child abuse prevention month in the context of COVID-19. Center for Innovation in Child Maltreatment Policy, Research and Training, Washington University in St. Louis. (2020). Available online at: https://cicm.wustl.edu/childabuseprevention-month-in-the-context-of-covid-19 (accessed November 2, 2020).

18. Uwezo. Are Our Children Learning? The Status of Remote-learning among School going Children in Kenya during the Covid-19 Crisis. Nairobi: Usawa Agenda. (2020).

19. The World Bank. Education Systems' Response to COVID-19. The World Bank. (2020). Avaialble online at: http://pubdocs.worldbank.org/en/ 673321594645490476/Education- Sector-Brief-July-12th.pdf （accessed November 2, 2020).

20. Goulds S, Fergus I, Gallinetti J. Living Under Lockdown: Girls and COVID-19. United Kingdom: Plan International. (2020). Available online at: https://planinternational.org/publications/living-under-lockdown (accessed November 2, 2020).

21. Bandiera O, Buehren N, Goldstein MP, Rasul I, Smurra A. The Economic Lives of Young Women in the Time of Ebola: Lessons from an Empowerment Program. The World Bank. (2019). doi: 10.1596/1813-945 $0-8760$

22. Griffith AK. Parental burnout and child maltreatment during the COVID-19 pandemic. J Family Violence. (2020) 2:1-7. doi: 10.1007/s10896-020-00172-2

23. Parsitau DS, Jepkemei E. How school closures during COVID-19 further marginalize vulnerable children in Kenya. Brookings. (2020). Available online at: https://www.brookings.edu/blog/education-plus-development/2020/05/ 06/how-school_closures-during-covid-19-further-marginalize-vulnerablechildren-in-kenya/ (accessed November 2, 2020).

24. Witaba B. Kenyan families suffer spillover effects from school closures. Global Voices. (2020). Available online at: https://globalvoices.org/2020/08/ 11/kenyan-families suffer-spillover-effects-from-school-closures/ (accessed November 2, 2020).

25. Kariuki, N. (2020, May 3). Child marriage: an overlooked evil as Kenya fights Covid-19 pandemic. Nation. Retrieved from: https://nation.africa/kenya/lifeand-style/dn2/child-marriage-an-overlooked-evil-as-kenya-fights-covid19-pandemic- 493416 (accessed February 10, 2021).

26. Odhiambo A. How girls' education and safety will be harmed by the covid response. Humans Rights Watch. (2020). Available online at: https://www.hrw.org/news/2020/04/15/how-girls-education-and-safetywill-be-harmed_covid (accessed November 2, 2020).

27. Woodhams J, Komarzynska K. The effect of mental disorder on crime scene behavior, its consistency, and variability. In: Woodhams J, Bennell C, editors, Crime linkage: Theory, research, and practice. Boca Raton, FL: CRC Press (2014). p. 55-82. doi: 10.1201/b17591-5 
28. Harris DA. Offence specialization and versatility in men convicted of sexual offences and referred for civil commitment. (2008). (Doctoral dissertation) Griffith University. Logan, QLD, United States.

29. Abel GG, Becker JV, Cunningham-Rathner J, Mittelman M, Rouleau JL. Multiple paraphilic diagnoses among sex offenders. J Am Acad Psychiatr Law Online. (1988) 16:153-68.

30. Heil P, Ahlmeyer S, Simons D. Crossover sexual offenses. Sexual Abuse. (2003) 15:221-36. doi: 10.1177/107906320301500401

31. Cann J, Friendship C, Gozna L. Assessing crossover in a sample of sexual offenders with multiple victims. Legal Criminol Psychol. (2007) 12:14963. doi: 10.1348/135532506X112439

32. Chiu YN, Leclerc B, Reynald DM, Wortley R. Situational crime prevention in sexual offenses against women: offenders tell us what works and what doesn't. Int J Offender Ther Comparat Criminol. (2020). doi: 10.1177/0306624X20919712. [Epub ahead of print].

33. Leclerc B, Chiu YN, Cale J, Cook A. Sexual violence against women through the lens of environmental criminology: toward the accumulation of evidencebased knowledge and crime prevention. Eur J Criminal Policy Res. (2016) 22:593-617. doi: 10.1007/s10610-015-9300-z

34. Nuttall CP. Handbook on planning and action for crime prevention in Southern Africa and the Caribbean regions. United Nations Office on Drugs and Crime. (2008).

35. Shaw M. Handbook on the Crime Prevention Guidelines: Making Them Work. Criminal Justice Handbook Series. Vienna, Austria: United Nations. (2010).

36. Mirghani Z, Karugaba J, Martin-Achard N, Undie CC, Birungi H. Community engagement in $S G B V$ prevention and response: a compendium of interventions in the East and Horn of Africa and the Great Lakes region. World Bank. (2017) 1-27. doi: 10.31899/rh7.1011
37. Usher K, Bhullar N, Durkin J, Gyamfi N, Jackson D. Family violence and COVID-19: increased vulnerability and reduced options for support. Int $J$ Mental Health Nursing. (2020) 29:549-52. doi: 10.1111/inm. 12735

38. McMahon PM. The public health approach to the prevention of sexual violence. Sexual Abuse. (2000) 12:27-36. doi: 10.1177/107906320001200104

39. Montesanti SR, Thurston WE. Mapping the role of structural and interpersonal violence in the lives of women: implications for public health interventions and policy. BMC Women's Health. (2015) 15:113. doi: 10.1186/s12905-015-0256-4

40. Ligiero D, Hart C, Fulu E, Thomas A, Radford L. What works to prevent sexual violence against children: Evidence Review. Together for Girls. (2019). Avaialble online at: www.togetherforgirls.org/svsolutions

41. Oduor C, Acosta F, Makhanu E. The adoption of mobile technology as a tool for situational crime prevention in Kenya. In: 2014 IST-Africa Conference Proceedings. (2014). p. 1-7. doi: 10.1109/ISTAFRICA.2014.6880669

Conflict of Interest: The authors declare that the research was conducted in the absence of any commercial or financial relationships that could be construed as a potential conflict of interest.

Copyright (c) 2021 Stevens, Rockey, Rockowitz, Kanja, Colloff and Flowe. This is an open-access article distributed under the terms of the Creative Commons Attribution License (CC BY). The use, distribution or reproduction in other forums is permitted, provided the original author(s) and the copyright owner(s) are credited and that the original publication in this journal is cited, in accordance with accepted academic practice. No use, distribution or reproduction is permitted which does not comply with these terms. 